\title{
FTO gene variants are strongly associated with type 2 diabetes in South Asian Indians
}

\author{
C. S. Yajnik • C. S. Janipalli • S. Bhaskar • \\ S. R. Kulkarni • R. M. Freathy • S. Prakash • \\ K. R. Mani • M. N. Weedon • S. D. Kale • J. Deshpande • \\ G. V. Krishnaveni • S. R. Veena • C. H. D. Fall • \\ M. I. McCarthy • T. M. Frayling • A. T. Hattersley • \\ G. R. Chandak
}

Received: 4 June 2008 /Accepted: 25 September 2008 / Published online: 13 November 2008

(C) Springer-Verlag 2008

\begin{abstract}
Aims and hypothesis Variants of the FTO (fat mass and obesity associated) gene are associated with obesity and type 2 diabetes in white Europeans, but these associations
\end{abstract}

C. S. Janipalli, S. Bhaskar, S. R. Kulkarni and R. M. Freathy contributed equally to this study.

Electronic supplementary material The online version of this article (doi:10.1007/s00125-008-1186-6) contains supplementary material, which is available to authorised users.

C. S. Yajnik · S. R. Kulkarni · S. D. Kale · J. Deshpande

Diabetes Unit,

King Edward Memorial Hospital and Research Centre,

Rasta Peth,

Pune, India

C. S. Janipalli $\cdot$ S. Bhaskar $\cdot$ S. Prakash $\cdot$ K. R. Mani $\cdot$

G. R. Chandak $(\bowtie)$

Genome Research Group,

Centre for Cellular and Molecular Biology,

Uppal Road,

Hyderabad 500 007, India

e-mail: chandakgre@ccmb.res.in

e-mail: chandakgre@gmail.com

R. M. Freathy $\cdot$ M. N. Weedon - T. M. Frayling $\cdot$ A. T. Hattersley Genetics of Complex Traits, Institute of Biomedical and Clinical Science,

Peninsula Medical School,

Exeter, UK

R. M. Freathy $\cdot$ M. N. Weedon $\cdot$ T. M. Frayling $\cdot$

A. T. Hattersley $(\square)$

Diabetes Genetics Group,

Institute of Biomedical and Clinical Science,

Peninsula Medical School,

Barrack Road,

Exeter EX2 5DW, UK

e-mail: A.T.Hattersley@ex.ac.uk are not consistent in Asians. A recent study in Asian Indian Sikhs showed an association with type 2 diabetes that did not seem to be mediated through BMI. We studied the association of FTO variants with type 2 dia-

G. V. Krishnaveni $\cdot$ S. R. Veena Holdsworth Memorial Hospital, Mysore, India

C. H. D. Fall

Medical Research Council, Epidemiology Resource Centre,

University of Southampton,

Tremona Road,

Southampton, UK

\section{I. McCarthy}

Wellcome Trust Centre for Human Genetics,

University of Oxford,

Roosevelt Drive,

Oxford, UK

M. I. McCarthy

Oxford Centre for Diabetes, Endocrinology and Metabolism,

University of Oxford, Churchill Hospital,

Oxford, UK 
betes and measures of obesity in South Asian Indians in Pune.

Methods We genotyped, by sequencing, two single nucleotide polymorphisms, rs9939609 and rs7191344, in the FTO gene in 1,453 type 2 diabetes patients and 1,361 controls from Pune, Western India and a further 961 populationbased individuals from Mysore, South India.

Results We observed a strong association of the minor allele A at rs9939609 with type 2 diabetes (OR per allele $1.26 ; 95 \%$ CI $1.13-1.40 ; p=3 \times 10^{-5}$ ). The variant was also associated with BMI but this association appeared to be weaker $(0.06 \mathrm{SDs}$; 95\% CI 0.01-0.10) than the previously reported effect in Europeans (0.10 SDs; 95\% CI 0.09-0.12; heterogeneity $p=0.06)$. Unlike in the Europeans, the association with type 2 diabetes remained significant after adjusting for BMI (OR per allele for type 2 diabetes 1.21; $95 \%$ CI 1.06-1.37; $p=4.0 \times 10^{-3}$ ), and also for waist circumference and other anthropometric variables.

Conclusions Our study replicates the strong association of FTO variants with type 2 diabetes and similar to the study in North Indians Sikhs, shows that this association may not be entirely mediated through BMI. This could imply underlying differences between Indians and Europeans in the mechanisms linking body size with type 2 diabetes.

Keywords Body mass index $\cdot$ Ethnicity $\cdot$ FTO .

Polymorphisms · Type 2 diabetes mellitus

\section{Abbreviation}

SNP Single nucleotide polymorphism

\section{Introduction}

Common variants of the FTO (fat mass and obesity associated) gene have been found to be strongly associated with BMI, obesity and type 2 diabetes in white European adults and children [1, 2]; the association with type 2 diabetes was entirely explained by the association with BMI. The association of FTO variants with type 2 diabetes and BMI has been independently identified in several white European populations [3] but the findings are somewhat inconsistent in Asians, which may be the result of varying study designs, inadequate sample sizes or ethnic differences [4-6]. India is called the 'diabetes capital of the world'. Indians develop diabetes at a much lower BMI than that in white Europeans, and for any given BMI Indians have a higher prevalence of diabetes [7]. A recent study in North Indian Sikhs showed a strong association of FTO variants with type 2 diabetes, which did not seem to be mediated through BMI [8]. This raises the possibility that the association of FTO variants with BMI and type 2 diabetes might be different in Asian populations. We studied the association of FTO variants with type 2 diabetes and different measures of obesity in Pune, India.

\section{Methods}

Study participants - patients and controls The data reported in this study were obtained from 1,453 type 2 diabetes patients of Indo-European ethnicity, diagnosed before 45 years of age, as reported earlier [9]. The study also included two groups of controls comprising 1,361 and 961 non-diabetic participants of Indo-European and Dravidian ethnicity, respectively (see Electronic supplementary material $[\mathrm{ESM}])$. Participants in both the cohorts have been extensively phenotyped for different biochemical-metabolic and anthropometric variables.

Genotyping and replication analysis Samples were genotyped for two single nucleotide polymorphisms (SNPs), rs9939609 and rs7191344, in the FTO gene by sequencing. Genotypes for $\sim 10 \%$ samples $(n=516)$ were validated by re-genotyping them using other genotyping platforms that did not detect any error $(0 / 516)$.

Statistical analysis We used logistic regression to investigate the association between type 2 diabetes and the FTO genotype in Indo-European patients and non-diabetic controls, while linear regression was used to analyse the association between the FTO genotype and BMI or other anthropometric measures. Finally, meta-analysis was performed to combine the linear regression coefficients from within the three cohorts, using study- and sex-specific $Z$-scores for BMI (see ESM). All statistical analyses were carried out using STATA (version 9; Stata Corporation, College Station, TX, USA) and inter-study heterogeneity was estimated using Cochran's Q test and the $I^{2}$ statistic [10]. Power calculations were performed using QUANTO v.1. 2. (http://hydra.usc.edu/ gxe). The Indo-European case-control study had $>92 \%$ power to detect the association between FTO genotype and type 2 diabetes observed in the European populations (OR 1.27 [1]; log-additive model) at $\alpha=0.01$, given the minor allele frequency in Indians (0.30). Although the Indo-European cases $(n=1,448)$ and controls $(n=1,355)$ and Dravidian $(n=960)$ studies individually had limited power to detect the $0.1 \mathrm{SD}$ per allele association with BMI seen in Europeans at $\alpha=0.01$ (power $46 \%, 43 \%$ and 29\%, respectively), the meta-analysis $(n=3,763)$ gave $>85 \%$ power.

\section{Results}

We compared the distribution of genotypes in 1,453 type 2 diabetes patients and 1,361 non-diabetic controls of Indo- 
Table 1 Basic characteristics of patients and control groups
Values are mean (SD) for all variables except for FPG, $2 \mathrm{~h}$ PG, FPI and $2 \mathrm{~h} \mathrm{PI}$, which are median (interquartile range) DEXA, dual-energy X-ray absorptiometry; FPG, fasting plasma glucose; FPI, fasting plasma insulin; HOMA-R, homeostasis model assessment of insulin resistance; $2 \mathrm{~h} \mathrm{PG}$, $2 \mathrm{~h}$ plasma glucose; $2 \mathrm{~h}$ PI, $2 \mathrm{~h}$ plasma insulin; TC, plasma total cholesterol; TG, plasma triacylglycerol

\begin{tabular}{|c|c|c|c|}
\hline \multirow[t]{2}{*}{ Characteristic } & \multirow[t]{2}{*}{ Patients } & \multicolumn{2}{|l|}{ Controls } \\
\hline & & Pune & Parthenon \\
\hline$N$ & 1,453 & 1,361 & 961 \\
\hline \multicolumn{4}{|l|}{ Sex } \\
\hline Male $(\%)$ & $818(56.3)$ & $729(53.6)$ & $446(46.4)$ \\
\hline Female $(\%)$ & $635(43.7)$ & $632(46.4)$ & $515(53.6)$ \\
\hline Present age (years) & $46.6(9.3)$ & $34.5(6.1)$ & $32.4(5.9)$ \\
\hline Age at diagnosis (years) & $37.0(16.4)$ & - & - \\
\hline Ethnicity & Indo-European & Indo-European & Dravidian \\
\hline Systolic blood pressure $(\mathrm{mmHg})$ & $128(16)$ & $116(14)$ & $112(13)$ \\
\hline Diastolic blood pressure $(\mathrm{mmHg})$ & $80(9)$ & $69(10)$ & $69(10)$ \\
\hline Height $(\mathrm{cm})$ & $160.9(9.1)$ & $159.7(8.5)$ & $160.4(8.7)$ \\
\hline Weight (kg) & $67.8(12.0)$ & $55.0(11.9)$ & $61.4(12.5)$ \\
\hline \multicolumn{4}{|l|}{$\operatorname{BMI}\left(\mathrm{kg} / \mathrm{m}^{2}\right)$} \\
\hline Male & $25.4(4.0)$ & $21.9(3.6)$ & $23.9(3.6)$ \\
\hline Female & $27.2(4.3)$ & $20.9(4.1)$ & $23.6(4.5)$ \\
\hline \multicolumn{4}{|l|}{ Waist circumference $(\mathrm{cm})$} \\
\hline Male & $95.4(10.7)$ & $83.2(10.5)$ & $86.3(10.3)$ \\
\hline Female & $92.4(10.3)$ & $69.9(10.4)$ & $82.1(11.9)$ \\
\hline \multicolumn{4}{|l|}{ Hip circumference $(\mathrm{cm})$} \\
\hline Male & $97.3(7.4)$ & $91.6(7.5)$ & $92.8(7.4)$ \\
\hline Female & $103.2(10.2)$ & $90.9(9.3)$ & $92.5(8.7)$ \\
\hline \multicolumn{4}{|l|}{ WHR } \\
\hline Male & $0.98(0.06)$ & $0.91(0.06)$ & $0.93(0.06)$ \\
\hline Female & $0.89(0.06)$ & $0.77(0.06)$ & $0.88(0.07)$ \\
\hline \multicolumn{4}{|l|}{ Fat mass percentage by DEXA } \\
\hline Male & - & $17.7(8.4)$ & - \\
\hline Female & - & $27.3(8.7)$ & - \\
\hline FPG $(\mathrm{mmol} / \mathrm{l})$ & $8.50(6.89-11.28)$ & $5.06(4.61-5.56)$ & $5.49(5.11-5.88)$ \\
\hline 2 h PG $(\mathrm{mmol} / \mathrm{l})$ & $13.17(10.72-16.39)$ & $5.50(4.56-6.72)$ & $5.94(5.09-6.74)$ \\
\hline FPI (pmol/l) & - & $32.8(20.6-48.7)$ & $44.8(30.1-69.1)$ \\
\hline 2 h PI (pmol/l) & - & $173.3(97.9-319.9)$ & $246.9(160.6-378.3)$ \\
\hline $\mathrm{TC}(\mathrm{mmol} / \mathrm{l})$ & $4.19(0.98)$ & $3.91(0.86)$ & $4.30(0.91)$ \\
\hline $\mathrm{TG}(\mathrm{mmol} / \mathrm{l})$ & $1.66(1.12)$ & $1.09(0.81)$ & $1.57(1.17)$ \\
\hline $\operatorname{HDLC}(\mathrm{mmol} / \mathrm{l})$ & $1.06(0.25)$ & $1.07(0.32)$ & $1.06(0.22)$ \\
\hline HOMA-R & - & $1.85(1.89)$ & $2.17(1.54)$ \\
\hline
\end{tabular}

European ethnicity (Table 1). The minor allele $\mathrm{A}$ at rs9939609 in the FTO gene had a frequency of 0.30 in controls and the genotypes were in Hardy-Weinberg equilibrium. The A allele was strongly associated with type 2 diabetes (OR per allele 1.26; 95\% CI 1.13-1.40; $p=3 \times$
$10^{-5}$ ) (Table 2), but not with BMI either in patients $(p=0.29)$ or in controls $(p=0.82)$ and not with other anthropometric variables (Table 3 ). The association of the FTO genotype with type 2 diabetes remained significant after adjusting for BMI (OR per allele for type 2 diabetes 1.21;

Table 2 Allelic and genotypic frequency and estimate of relative risk for FTO variant rs9939609 in type 2 diabetes patients and control participants (Indo-Europeans)

\begin{tabular}{|c|c|c|c|c|c|c|c|c|c|}
\hline SNP & $\begin{array}{l}\text { Position } \\
(\text { NCBI 36.3) }\end{array}$ & Allele & $\begin{array}{l}\text { Patients } \\
(n=1,453)\end{array}$ & $\begin{array}{l}\text { Controls } \\
(n=1,361)\end{array}$ & Genotype & $\begin{array}{l}\text { Patients } \\
(n=1,453)\end{array}$ & $\begin{array}{l}\text { Controls } \\
(n=1,361)\end{array}$ & $\begin{array}{l}\text { Allele OR } \\
(95 \% \mathrm{CI})\end{array}$ & $p$ value \\
\hline \multirow{3}{*}{ rs9939609 } & \multirow{3}{*}{52378028} & $\mathrm{~T}$ & 0.646 & 0.700 & $\mathrm{TT}$ & $633(43.6)$ & $678(49.8)$ & & \\
\hline & & & & & TA & $613(42.2)$ & $550(40.4)$ & & \\
\hline & & $\mathrm{A}$ & 0.354 & 0.300 & AA & $207(14.2)$ & $133(9.8)$ & $1.26(1.13-1.40)$ & $3.0 \times 10^{-5}$ \\
\hline
\end{tabular}

Values in parentheses indicate percentage

${ }^{a}$ National Centre for Biotechnology Information, Build 36.3 


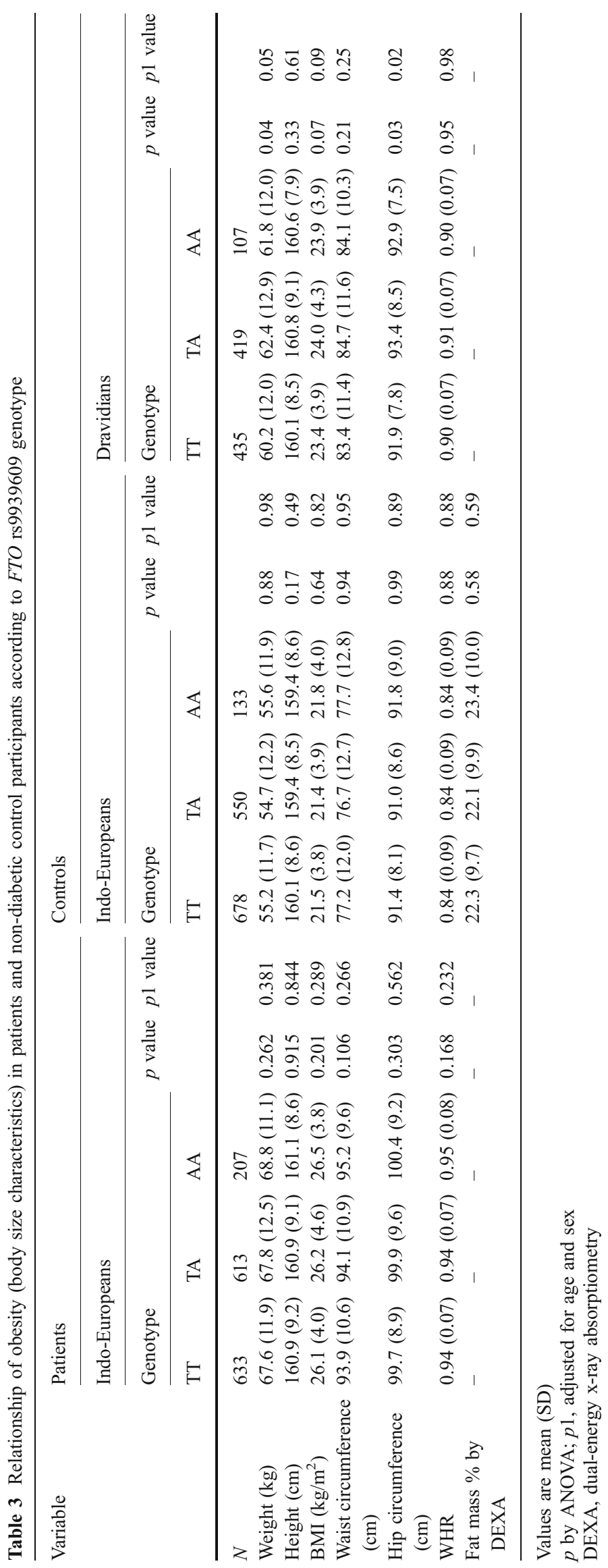


95\% CI $1.06-1.37 ; p=4 \times 10^{-3}$ ), for waist circumference (OR per allele $1.20 ; 95 \%$ CI $1.04-1.37 ; p=0.01$ ), for hip circumference (OR per allele $1.24 ; 95 \%$ CI $1.10-1.40$; $p=6 \times 10^{-4}$ ) or for WHR (OR per allele $1.22 ; 95 \%$ CI $\left.1.08-1.39 ; p=2 \times 10^{-3}\right]$. This suggests that the increased risk of developing type 2 diabetes in those participants with FTO variants was not entirely mediated through its effect on BMI or central obesity in our study. Analysis of non-diabetic Dravidian controls showed a similar lack of association with BMI and other anthropometric variables (Table 3). Another SNP rs7193144, which is highly correlated with rs9939609 $\left(r^{2}=1.0\right)$ in Europeans [1, 2] and in our study $\left(r^{2}=0.99\right)$, showed a similar association with type 2 diabetes (OR 1.31; $95 \%$ CI $1.12-1.54 ; p=8.2 \times 10^{-4}$ ) but was not associated with BMI or other anthropometric variables (data not presented). We performed a meta-analysis combining IndoEuropean cases, Indo-European controls and Dravidian controls $(n=3,763)$ and observed a borderline association between FTO genotype and BMI (per allele SD change in $\log _{10}$ BMI $0.06 ; 95 \%$ CI $0.01-0.10 ; p=0.017 ; I^{2}=0 \%$; Fig. 1), waist circumference (per allele SD change in $\log _{10}$ waist circumference $0.05 ; 95 \%$ CI $0.01-0.10 ; p=0.030$; $I^{2}=0 \%$ ) and hip circumference (per allele SD change in hip circumference $0.05 ; 95 \%$ CI $0.01-0.10 ; p=0.027 ; I^{2}=0 \%$ ), but not WHR $(p=0.42)$. The FTO genotype at rs 9939609 was not associated with traits associated with obesity including glycaemia, insulin concentrations, insulin resistance (by homeostasis model assessment of insulin resistance) or lipids in Indo-Europeans but was associated with fasting plasma insulin levels in Dravidians (see ESM Table 1).

\section{Discussion}

Our results demonstrate that in Asian Indians, variants in the FTO gene predispose to type 2 diabetes; however, unlike in Europeans, they do not appear to do this entirely through their influence on BMI, central obesity and adiposity $[1,2]$. Sanghera et al. [8] recently reported a significant association of FTO gene variants with type 2 diabetes in North Indian Sikhs that was unaffected by controlling for BMI. They suggested that ethnic differences were responsible for the variable results. A recent study in East Asians also found borderline evidence that the association of the FTO gene with BMI was weaker compared with that in studies of Europeans, but the association with type 2 diabetes was similar [6]. The finding that the FTO variants are associated with type 2 diabetes argues against a difference in linkage disequilibrium with a putative functional variant in these two populations. Although population stratification may be a possible explanation that may confound the results, recent evidence suggests that despite the geographic and linguistic diversity, Indians as a whole display a low level of genetic heterogeneity [11]. Recent studies in Chinese and Japanese populations did not find an association of FTO variants with type 2 diabetes, but a weak association with BMI was found in Japanese [4, 5]. Another study reported that FTO variants
Fig. 1 Meta-analysis plot for FTO variant rs9939609 and BMI association for the present study and comparison with the European study of Frayling et al. [1]

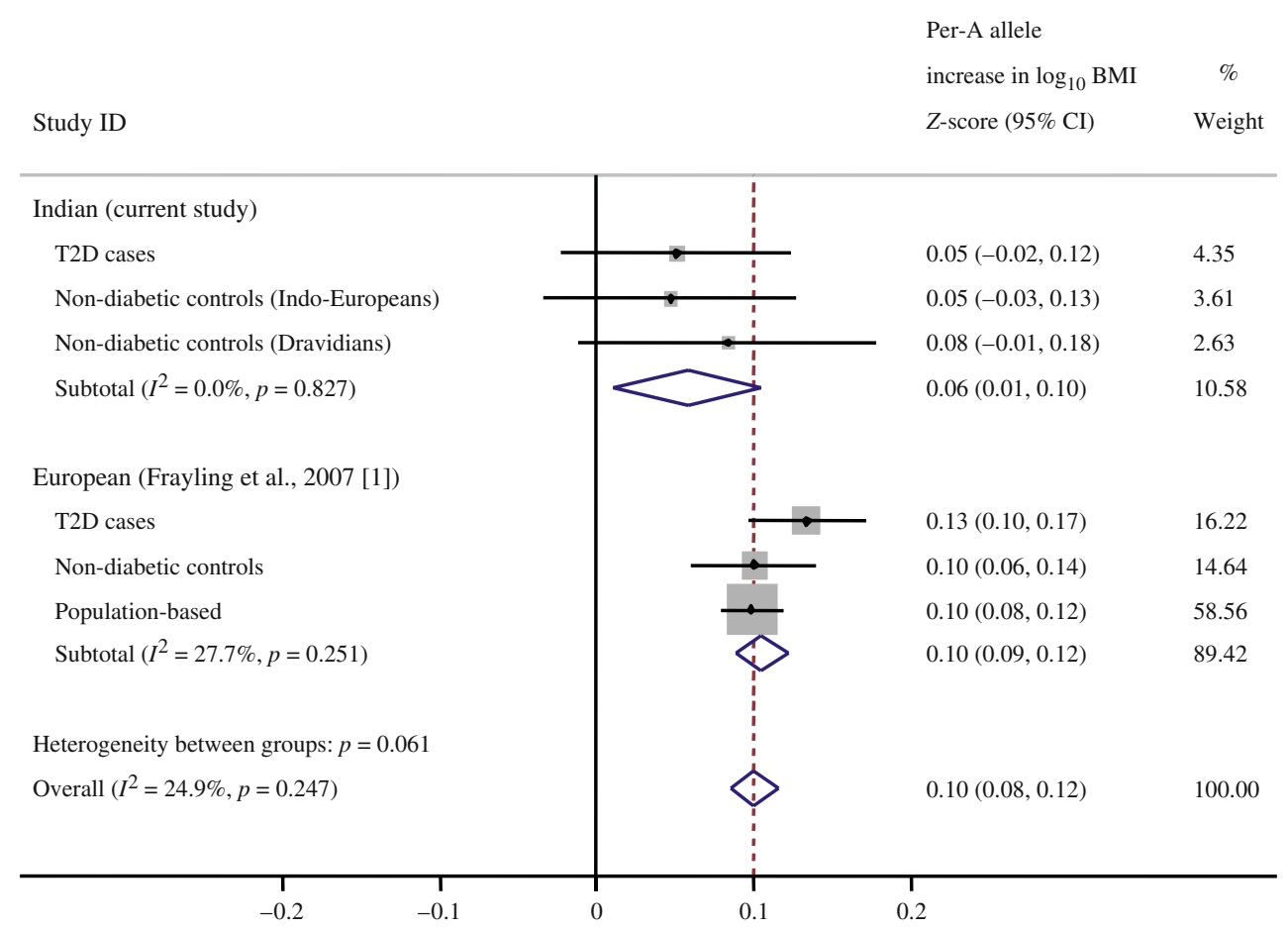


might influence the risk of severe obesity in the Japanese [6]. The frequencies of the A allele at the rs9939609 variant were lower in Chinese (0.12) and Japanese (0.18) populations compared with those in Europeans (0.45) and Indians (0.30), meaning that the studies in East Asians have less power [4-6]. It is well known that Indians (and Asians in general) have a lower BMI than Europeans, and the relationship between obesity measures and risk of type 2 diabetes is steeper [7]. This has been ascribed to relatively higher central obesity (WHR) and higher adiposity (body fat percentage) in Asians for a given BMI compared with that in Europeans [7]. The association between $F T O$ variants and type 2 diabetes in this study, independent of measures of obesity, could indicate that BMI is a poor measure of adiposity in South Asian Indians. However, the possibility remains that there could be underlying differences in the way the FTO gene works to influence the risk of type 2 diabetes in Asian Indians and in Europeans.

The functional role of the FTO gene is not yet understood, nor is it clear how the variants affect body size and predict the risk of type 2 diabetes. Based on sequence homology, the FTO gene is predicted to code for a 2-oxoglutaratedependent demethylase enzyme [12], which influences nucleic acid demethylation and so may be important in epigenetic regulation. It is intriguing that maternal vitamin $\mathrm{B}_{12}$ and folate nutrition influenced adiposity and insulin resistance in Indian children [13], suggesting that 1-carbon (methyl) metabolism may have an important role in predicting risk for type 2 diabetes. It would be interesting to see if the micronutrients mentioned above influence the effect of the FTO gene on adiposity.

In conclusion, our results demonstrate that in Indians, variants of the FTO gene predispose to type 2 diabetes, but not entirely through their effect on BMI. Our results are consistent with those recorded in North Indian Sikhs but an independent replication of the weaker effect of FTO variants on BMI is required [8]. These results suggest a difference in the possible mechanism of the association from that in Europeans and reinforce our previous suggestion that the relationship between BMI and type 2 diabetes may be different in Indians. Comparative studies of FTO in South Asians and Europeans, including functional genomic and epigenetic analyses, may help to understand critical mechanisms in the pathogenesis of obesity and type 2 diabetes.

Acknowledgements We thank all the patients and control participants for agreeing to take part in the study. We gratefully acknowledge the contributions made by many colleagues involved in sample collection, phenotyping, DNA extraction, data collection and data management. The WellGen study, Pune Maternal Nutrition Study and Pune Children Study were supported by the Wellcome Trust, London,
UK, while Coronary Risk of Insulin Sensitivity in Indian Subjects study was funded by Nestle Foundation, Lausanne, Switzerland. The Parthenon study was initiated by the former MRC Epidemiology Unit (Southampton) and was funded by the British Heart Foundation, UK. Financial support from the Council of Scientific and Industrial Research, Government of India under the Network Programme (NWP0032) is gratefully acknowledged. We thank S. Sirdeshpande, P. Yajnik and N. Chandak for their support of these studies.

Duality of interest The authors declare that there is no duality of interest associated with this manuscript.

\section{References}

1. Frayling TM, Timpson NJ, Weedon MN et al (2007) A common variant in the FTO gene is associated with body mass index and predisposes to childhood and adult obesity. Science 316:889-894

2. Zeggini E, Weedon MN, Lindgren CM et al (2007) Replication of genome-wide association signals in UK samples reveals risk loci for type 2 diabetes. Science 316:1336-1341

3. Dina C, Meyre D, Gallina S, Durand E et al (2007) Variation in FTO contributes to childhood obesity and severe adult obesity. Nat Genet 39:706-707

4. Li H, Wu Y, Loos RJ et al (2008) Variants in the fat mass- and obesity-associated (FTO) gene are not associated with obesity in a Chinese Han population. Diabetes 57:264-268

5. Hotta K, Nakata Y, Matsuo T et al (2008) Variations in the FTO gene are associated with severe obesity in the Japanese. J Hum Genet 53:546-553

6. Ng MC, Park KS, Oh B et al (2008) Implication of genetic variants near TCF7L2, SLC30A8, HHEX, CDKAL1, CDKN2A/B, $I G F 2 B P 2$ and $F T O$ in type 2 diabetes and obesity in 6719 Asians. Diabetes 57:2226-2233

7. Ramachandran A, Snehalatha C, Viswanathan V, Viswanathan M, Haffner SM (1997) Risk of non-insulin-dependent diabetes mellitus conferred by obesity and central obesity in different ethnic groups. A comparative analysis between Asian Indians, Mexican Americans and whites. Diabetes Res Clin Pract 36:121125

8. Sanghera DK, Ortega L, Han S et al (2008) Impact of nine common type 2 diabetes risk polymorphisms in Asian Indian Sikhs: PPARG2 (Pro12Ala), IGF2BP2, TCF7L2 and FTO variants confer a significant risk. BMC Med Genet 9:59-67

9. Chandak GR, Janipalli CS, Bhaskar S et al (2007) Common variants in the TCF7L2 gene are strongly associated with type 2 diabetes mellitus in the Indian population. Diabetologia 50:63-66

10. Higgins JP, Thompson SG, Deeks JJ, Altman DG (2003) Measuring inconsistency in meta-analyses. BMJ 327:557-560

11. Rosenberg NA, Mahajan S, Gonzalez-Quevedo C et al (2006) Low levels of genetic divergence across geographically and linguistically diverse populations from India. PloS Genet 2:2052-2061

12. Gerken T, Girard CA, Tung YC et al (2007) The obesityassociated $F T O$ gene encodes a 2-oxoglutarate-dependent nucleic acid demethylase. Science 30:1469-1472

13. Yajnik CS, Deshpande SS, Jackson AA et al (2008) Vitamin $B_{12}$ and folate concentrations during pregnancy and insulin resistance in the offspring: the Pune Maternal Nutrition Study. Diabetologia 51:29-38 